\title{
Outcomes of decompression without fusion in patients with lumbar spinal stenosis and substantial back pain
}

\author{
Rachid Bech-Azeddine, PhD, ${ }^{1,2}$ Søren Fruensgaard, MD, ${ }^{3}$ Mikkel Andersen, MD,, 45 and \\ Leah Y. Carreon, MD, MSc ${ }^{4,5}$

\begin{abstract}
${ }^{1}$ Center for Rheumatology and Spine Diseases, Rigshospitalet Glostrup; 2Department of Clinical Medicine, University of Copenhagen; ${ }^{3}$ Department of Orthopedic Surgery, Regionshospitalet Silkeborg; ${ }^{4}$ Center for Spine Surgery and Research, Middelfart Hospital, Middelfart; and ${ }^{5}$ Department of Regional Health Research, University of Southern Denmark, Odense, Denmark
\end{abstract}

\begin{abstract}
OBJECTIVE The predominant symptom of lumbar spinal stenosis (LSS) is neurogenic claudication or radicular pain. Some surgeons believe that the presence of substantial back pain is an indication for fusion, and that decompression alone may lead to worsening of back pain from destabilization associated with facet resection. The purpose of this study was to determine if patients with LSS and clinically significant back pain could obtain substantial improvements in back pain after a decompression alone without fusion.
\end{abstract}

METHODS The DaneSpine database was used to identify 2737 patients with LSS without segmental instability and a baseline back pain visual analog scale (VAS) score $\geq 50$ who underwent a decompression procedure alone without fusion. Standard demographic and surgical variables and patient outcomes, including back and leg pain VAS score (0-100), Oswestry Disability Index (ODI), and EQ-5D at baseline and at 12 months postoperatively, were collected.

RESULTS A total of 1891 patients (69\%) had 12-month follow-up data available for analysis; the mean age was 66.4 years, 860 (46\%) were male, the mean BMI was $27.8 \mathrm{~kg} / \mathrm{m}^{2}$, and $508(27 \%)$ were current smokers. At 12 months postoperatively, there were statistically significant improvements $(p<0.001)$ from baseline for back pain $(72.1$ to 42.1$)$, leg pain (71.2 to 41.3), EQ-5D (0.35 to 0.61), and ODI (44.1 to 27.8).

CONCLUSIONS Patients with LSS, clinically substantial back pain, and no structural instability obtain improvement in back pain after decompression-only surgery and do not need a concomitant fusion.

https://thejns.org/doi/abs/10.3171/2020.8.SPINE20684

KEYWORDS back pain; lumbar decompression; lumbar spinal stenosis; patient-reported outcomes; Oswestry Disability Index; EQ-5D

$\mathrm{L}$ UMBAR spinal stenosis (LSS) is caused by a combination of factors, including hypertrophy of joint capsules and ligaments, intervertebral disc protrusion, loss of intervertebral space height, and osteophytes. Surgery with decompression for LSS is the most common operation for degenerative spinal disease in the aging population. ${ }^{1}$ There is substantial evidence for a superior clinical improvement by surgical decompression compared to prolonged conservative treatment. ${ }^{2-4}$

The predominant symptom and main indication for decompression is neurogenic claudication or radicular pain, but low-back pain is also a common complaint. In the presence of predominant back pain, some authors recommend a concomitant fusion to alleviate the back pain. ${ }^{5,6}$ However, performing a supplemental fusion procedure involves increased blood loss, operative duration, hospital stay, complication rate, and overall surgical cost. ${ }^{78}$ Recent studies have suggested an acceptable improvement of back pain with decompression only in patients with LSS. ${ }^{9-11}$ The aim of the present study was to clarify the clinical impact of decompression alone in patients with LSS and substantial back pain who were prospectively enrolled in the DaneSpine database. ${ }^{12}$

\section{Methods}

The DaneSpine database is a Danish national spine surgery database, prospectively collecting demographic and pre- and 12-month postoperative patient-reported outcomes (PROs). The database was queried to identify

ABBREVIATIONS LSS = lumbar spinal stenosis; MCID = minimal clinically important difference; ODI = Oswestry Disability Index; PRO = patient-reported outcome; VAS = visual analog scale.

SUBMITTED April 24, 2020. ACCEPTED August 17, 2020.

INCLUDE WHEN CITING Published online January 22, 2021; DOI: 10.3171/2020.8.SPINE20684. 
TABLE 1. Patient demographics

\begin{tabular}{lc}
\hline \multicolumn{1}{c}{ Variable } & Value \\
\hline No. of patients & 1891 \\
\hline Mean age (SD), yrs & $66.4(11.3)$ \\
\hline Males (\%) & $860(46)$ \\
\hline Smokers (\%) & $508(27)$ \\
\hline Mean BMI (SD), $\mathrm{kg} / \mathrm{m}^{2}$ & $27.8(5.0)$ \\
\hline
\end{tabular}

patients with the diagnosis of LSS without segmental instability and a baseline back pain visual analog scale (VAS) score $\geq 50$ who underwent a decompression procedure without fusion. No segmental instability was defined as a spondylolisthesis less than $3 \mathrm{~mm}$ and no further slip on functional radiographs. The primary indication for surgery was leg pain and/or leg symptoms characteristic of LSS with a symptom duration longer than 3 months despite conservative treatment. The patients were operated on at three different Danish Spine units, and all had MRI findings concordant with the clinical symptoms. The type of decompression was performed according to the individual preference of the surgeon.

The threshold of a VAS back pain score $\geq 50$ was selected, as this cutoff score might prompt some surgeons to add a fusion procedure. In concordance, a VAS back pain score $\geq 50$ is used as an inclusion criterion in an FDA investigational device exemption study evaluating an interspinous process device versus instrumented fusion. ${ }^{13}$

Demographic data were collected, including age, sex, height, weight, smoking status, surgical variables, patient outcomes including back and leg pain VAS scores (0-100), ${ }^{14}$ and Oswestry Disability Index (ODI) ${ }^{15}$ and EQ$5 \mathrm{D}^{16}$ at baseline and 12 months postoperatively. Hence, the present study represents a longitudinal retrospective study of prospectively collected data. Statistical analyses were conducted using SPSS (version 25.0, IBM Corp.), and paired t-tests were applied to compare baseline PROs with 12 -month PROs. The significance level was set at $\mathrm{p}<0.05$.

\section{Results}

A total of 2737 patients undergoing decompression for LSS and presenting VAS back pain scores $\geq 50$ were identified, of whom 1891 patients $(69 \%)$ had 12-month followup data available for analysis. The mean patient age was $66.4 \pm 11.3$ years, $860(46 \%)$ were male, the mean BMI was $27.8 \pm 5.0 \mathrm{~kg} / \mathrm{m}^{2}$, and 508 patients $(27 \%)$ were current smokers (Table 1).

At 12 months' postoperative follow-up, there were statistically significant improvements from baseline in VAS back pain, VAS leg pain, ODI, and EQ-5D ( $\mathrm{p}<0.001$, Table 2). The mean VAS back pain score was reduced from 72.1 to 42.1 , and VAS leg pain score from 71.2 to 41.3. The ODI improved from 44.1 to 27.8 and the EQ-5D from 0.35 to 0.61 . The ratio of patients reaching a minimal clinically important difference (MCID) was 59\% $(n=1123)$ for ODI $(\mathrm{MCID}=10),{ }^{17} 67 \%(\mathrm{n}=1269)$ for VAS back pain (MCID $=18),{ }^{17}$ and $57 \%(\mathrm{n}=1076)$ for VAS leg pain $(\mathrm{MCID}=$ 20). ${ }^{18}$
TABLE 2. Comparison of baseline and 12-month postoperative results

\begin{tabular}{lccc}
\hline \multicolumn{1}{c}{ Scale } & Baseline & 1-Yr Follow-Up & p Value \\
\hline VAS back pain, 0-100 & $72.1(13.6)$ & $42.1(30.0)$ & $<0.001$ \\
\hline VAS leg pain, 0-100 & $71.2(19.2)$ & $41.3(32.0)$ & $<0.001$ \\
\hline ODI, 0-100 & $44.1(15.4)$ & $27.8(19.5)$ & $<0.001$ \\
\hline EQ-5D, 0-1.0 & $0.35(0.31)$ & $0.61(0.31)$ & $<0.001$ \\
\hline
\end{tabular}

Values are presented as the mean (SD) unless indicated otherwise.

\section{Discussion}

The rate of lumbar decompression for LSS has been steadily increasing in the elderly over the last decades. ${ }^{19}$ The relief of neurogenic claudication after surgery is well documented by the current literature. ${ }^{2-4}$ However, in the context of predominant back pain, it is debated whether an additional fusion is indicated.

In the present longitudinal retrospective study of prospectively collected data, we investigated the clinical effect of decompression without fusion in a subgroup of patients with LSS with claudication and a concurrent substantial back pain VAS score $\geq 50$. We demonstrated statistically and clinically significant improvements in self-reported back pain, leg pain, mobility, and quality of life in patients at the 1-year follow-up, based on VAS scores for leg and back pain, the ODI, and the EQ-5D. ${ }^{15,20-22}$ The reduction in back pain was similar to the reduction in leg pain, and the improvement in back pain surpassed the MCID in $67 \%$ of the 1891 patients at 12 months' follow-up. The results strongly suggest that despite substantial back pain, decompression without fusion is an appropriate treatment for patients with LSS and neurogenic claudication.

Our results are in concordance with the findings of recent studies based on a considerably smaller patient sample. Including all patients undergoing decompression for spinal stenosis, regardless of level of back pain at baseline, both Geiger et al. and Srinivas et al., respectively, found significant improvement in low-back pain in 33 patients with a follow up $<100$ weeks, ${ }^{11}$ and in 677 patients at 12 months' follow-up, of whom $68 \%$ reached the MCID. ${ }^{9}$ Our study solely included patients with preoperative VAS back pain scores $\geq 50$. Our findings therefore emphasize that an additional fusion should not routinely be added to the decompression in patients with LSS, even though back pain is substantial.

Crawford et al. ${ }^{10}$ likewise only analyzed patients with back pain scores $\geq 50$, and also demonstrated a significant reduction in both leg and back pain at 12 months' followup in 726 patients. They stratified patients according to the dominant symptom into the subgroups back pain-predominant group, leg pain-predominant group, and back pain equal to leg pain group. The MCID in the 3 groups was reached for back pain in $80 \%, 86 \%$, and $84 \%$ of the patients, respectively.

The large sample size of the current cohort compared to previous studies constitutes a strength of the present study. Data were also collected prospectively. A potential weakness is that we did not stratify according to surgical technique of the decompression, which theoretically could 
influence the outcome. However, previous studies indicated that this variable does not play a defining role., ${ }^{9,11,23}$ Our 12 -month follow-up rate was $69 \%$, slightly higher compared to the abovementioned studies. A previous dropout analysis of the DaneSpine database showed no influence on conclusions, and overall the nonresponders showed a better improvement in EQ-5D compared to the responders. ${ }^{12}$ Thus, we do not believe the missing follow-up data confound the present findings. A longer follow-up than 12 months might show a different outcome, i.e., if the decompression entails a segmental instability over time, resulting in increasing back pain. However, a previous study with 10 years of follow-up showed sustained improvement in back pain. ${ }^{4}$

The impact of the length of substantial back pain might also influence the outcome. A short duration of back pain in the context of LSS may implicate back pain due to muscle spasms secondary to the leg symptoms. This type of back pain would theoretically be more amenable to improvement after the decompression relieves the leg symptoms. Conversely, a longer symptom duration of back pain might indicate degenerative changes as the underlying cause, which would not be alleviated by the decompression.

More patients in the present study reached an MCID for VAS back pain as compared to reaching an MCID for leg pain or ODI. We believe this is due to the inclusion criteria: only patients with a baseline VAS back pain score $\geq 50$ were included, regardless of their baseline VAS leg pain or ODI score. The VAS leg pain and ODI scores consequently represented a broader range. Because the threshold of MCID for pain scores following surgery is lower, the higher the baseline score is, and more patients were likely to reach an MCID for VAS back pain.

Some authors advocate that substantial preoperative back pain is a predictor of poor outcome after surgery for LSS. ${ }^{24}$ Our results, based on a large cohort of patients all presenting with substantial back pain, contradict this assumption. Our results are consistent with those of Srinivas et al., finding that an increased severity of back pain at baseline appeared to be associated with a higher likelihood of reaching the MCID for low-back pain improvement. ${ }^{9}$

\section{Conclusions}

In this study, patients with LSS, substantial back pain at baseline, and no structural instability obtained significant improvement in their back pain, comparable to their improvement in leg pain, after decompression-only surgery and may not need a concomitant fusion.

\section{References}

1. Turner JA, Ersek M, Herron L, Deyo R. Surgery for lumbar spinal stenosis. Attempted meta-analysis of the literature. Spine (Phila Pa 1976). 1992;17(1):1-8.

2. Weinstein JN, Tosteson TD, Lurie JD, et al. Surgical versus nonsurgical therapy for lumbar spinal stenosis. $N$ Engl J Med. 2008;358(8):794-810.

3. Malmivaara A, Slätis P, Heliövaara M, et al. Surgical or nonoperative treatment for lumbar spinal stenosis? A randomized controlled trial. Spine (Phila Pa 1976). 2007; $32(1): 1-8$.
4. Amundsen T, Weber H, Nordal HJ, et al. Lumbar spinal stenosis: conservative or surgical management?: A prospective 10-year study. Spine (Phila Pa 1976). 2000;25(11): 1424-1436.

5. Chou R, Baisden J, Carragee EJ, et al. Surgery for low back pain: a review of the evidence for an American Pain Society Clinical Practice Guideline. Spine (Phila Pa 1976). 2009; 34(10):1094-1109.

6. Omidi-Kashani F, Hasankhani EG, Ashjazadeh A. Lumbar spinal stenosis: who should be fused? An updated review. Asian Spine J. 2014;8(4):521-530.

7. Machado GC, Ferreira PH, Yoo RI, et al. Surgical options for lumbar spinal stenosis. Cochrane Database Syst Rev. 2016; 11:CD012421.

8. Försth P, Ólafsson G, Carlsson T, et al. A randomized, controlled trial of fusion surgery for lumbar spinal stenosis. $N$ Engl J Med. 2016;374(15):1413-1423.

9. Srinivas S, Paquet J, Bailey C, et al. Effect of spinal decompression on back pain in lumbar spinal stenosis: a Canadian Spine Outcomes Research Network (CSORN) study. Spine J. 2019;19(6):1001-1008.

10. Crawford CH III, Glassman SD, Mummaneni PV, et al. Back pain improvement after decompression without fusion or stabilization in patients with lumbar spinal stenosis and clinically significant preoperative back pain. J Neurosurg Spine. 2016;25(5):596-601.

11. Geiger MF, Bongartz N, Blume C, et al. Improvement of back and leg pain after lumbar spinal decompression without fusion. J Neurol Surg A Cent Eur Neurosurg. 2019;80(2):81-87.

12. Højmark K, Støttrup C, Carreon L, Andersen MO. Patientreported outcome measures unbiased by loss of follow-up. Single-center study based on DaneSpine, the Danish spine surgery registry. Eur Spine J. 2016;25(1):282-286.

13. Davis RJ, Errico TJ, Bae H, Auerbach JD. Decompression and Coflex interlaminar stabilization compared with decompression and instrumented spinal fusion for spinal stenosis and low-grade degenerative spondylolisthesis: two-year results from the prospective, randomized, multicenter, Food and Drug Administration Investigational Device Exemption trial. Spine (Phila Pa 1976). 2013;38(18):1529-1539.

14. Karcioglu O, Topacoglu H, Dikme O, Dikme O. A systematic review of the pain scales in adults: which to use? Am J Emerg Med. 2018;36(4):707-714.

15. Fairbank JC. Oswestry disability index. J Neurosurg Spine. 2014;20(2):239-241.

16. EuroQol Group. EuroQol-a new facility for the measurement of health-related quality of life. Health Policy. 1990; 16(3):199-208.

17. Hägg O, Fritzell $P$, Nordwall A. The clinical importance of changes in outcome scores after treatment for chronic low back pain. Eur Spine J. 2003;12(1):12-20.

18. Lauridsen HH, Hartvigsen J, Manniche C, et al. Responsiveness and minimal clinically important difference for pain and disability instruments in low back pain patients. $B M C$ Musculoskelet Disord. 2006;7:82.

19. Deyo RA, Mirza SK, Martin BI, et al. Trends, major medical complications, and charges associated with surgery for lumbar spinal stenosis in older adults. JAMA. 2010;303(13): 1259-1265.

20. Coretti S, Ruggeri M, McNamee P. The minimum clinically important difference for EQ-5D index: a critical review. Expert Rev Pharmacoecon Outcomes Res. 2014;14(2):221-233.

21. Glassman SD, Copay AG, Berven SH, et al. Defining substantial clinical benefit following lumbar spine arthrodesis. $J$ Bone Joint Surg Am. 2008;90(9):1839-1847.

22. Carreon LY, Glassman SD, Howard J. Fusion and nonsurgical treatment for symptomatic lumbar degenerative disease: a systematic review of Oswestry Disability Index and MOS Short Form-36 outcomes. Spine J. 2008;8(5):747-755. 
23. Overdevest GM, Jacobs W, Vleggeert-Lankamp C, et al. Effectiveness of posterior decompression techniques compared with conventional laminectomy for lumbar stenosis. $\mathrm{Co}$ chrane Database Syst Rev. 2015;(3):CD010036.

24. Aalto TJ, Malmivaara A, Kovacs F, et al. Preoperative predictors for postoperative clinical outcome in lumbar spinal stenosis: systematic review. Spine (Phila Pa 1976). 2006; 31(18):E648-E663.

\section{Disclosures}

Dr. Andersen receives consulting fees from Cerapedics, outside the submitted work. Dr. Carreon is a member of the University of Louisville Institutional Review Board; is on the Editorial Advisory Board of Spine, The Spine Journal, and Spine Deformity; receives consulting fees from the National Spine Health Foundation; and receives a salary from Norton Healthcare and the University of Southern Denmark. Researchers and PhD students affiliated with The Center for Spine Surgery and Research received financial support from Lillebælt Hospital Research Council, Lillebælt Hospital Development Council, SDU Faculty Scholarship, The Gangsted Foundation, Danish Rheumatism Association, Region of Southern Denmark's Ph.D. Pool, Region of Southern Denmark's Research Fund, Region Zealand and Region of Southern Denmark's Joint Research Fund, Independent Research Fund Denmark, A.P. Møller Foundation for the Promotion of Medicine, Inger Goldmann's Fund, IMK General Fund, Aase and Ejnar Danielsen's Fund, Chief Physician Jørgen Werner Schous and wife, Else-Marie Schou, born Wonge's Fund, Cerapedics, Foundation for the Promotion of Chiropractic Research and Postgraduate Education, Eli Lilly, Kroghs Scholarship, Ortotech, and the Guildal Foundation.

\section{Author Contributions}

Conception and design: Bech-Azeddine, Andersen, Carreon. Acquisition of data: Bech-Azeddine, Fruensgaard, Andersen. Analysis and interpretation of data: Bech-Azeddine, Andersen, Carreon. Drafting the article: Bech-Azeddine. Critically revising the article: all authors. Reviewed submitted version of manuscript: all authors. Approved the final version of the manuscript on behalf of all authors: Bech-Azeddine. Statistical analysis: Carreon. Administrative/technical/material support: Andersen. Study supervision: Carreon.

\section{Supplemental Information \\ Previous Presentations}

The results of this study were presented orally by Dr. Carreon at the 34th North American Spine Society Annual Meeting, September 25-28, 2019, in Chicago, Illinois, and at the 26th International Meeting on Advanced Spine Techniques, July 17-20, 2019, at the RAI Amsterdam Convention Centre in Amsterdam, the Netherlands.

\section{Correspondence}

Rachid Bech-Azeddine: Center for Rheumatology and Spine Diseases, Rigshospitalet Glostrup, Denmark. rbechazeddine@ dadlnet.dk. 